\title{
FORMAÇÃO HISTÓRICA DA REDE DE CIDADES DO VALE DO JEQUITINHONHA
}

\author{
Ralfo Matos \\ André Velloso
}

\section{1- INTRODUÇÃO}

O conceito original de "rede de cidades" foi útil para designar conexões espaciais focalizando o sistema de comunicações. Com o tempo, o seu uso veio focalizar a existência de conjuntos estruturados de cidades, nos quais houvessem relações econômicas constantes e significativas.

Em Geografia foram importantes os estudos sobre redes urbanas, notadamente a partir das contribuições de Christaller, Losh e Brian Berry. Privilegiou-se então a utilização dos métodos lógico-matemáticos, através dos quais procurava-se identificar características dominantes passíveis de mensuração, enfatizando aspectos funcionais, níveis de hierarquia e graus de influência entre as localidades.

No Brasil, tais estudos são escassos. Não causa surpresa o relativo desconhecimento da evolução da rede urbana brasileira, principalmente da rede constituída por cidades médias e pequenas, do ponto de vista do tamanho populacional. ${ }^{1}$

É interessante lembrar que, em Minas Gerais, algumas pesquisas empreendidas na década de setenta se orientavam pela busca do conhecimento acerca das cidades médias. Acreditava-se que através do incremento de alguns destes núcleos urbanos, poderiam ser minimizados problemas relacionados ao crescimento das grandes cidades mineiras. ${ }^{2}$

A rede de cidades de Minas Gerais, um dos primeiros estados a se urbanizar no país, remonta ao século XVIII, após a descoberta do ouro e do diamante. ${ }^{3}$ Com a perda do dinamismo econômico estritamente ligado à atividade minerária ocorreu um movimento populacional centrífugo, na direção das áreas periféricas à região central, o que fez expandir a fronteira da província tanto para o sul-sudoeste quanto para o norte-nordeste.

Tendo em vista o processo de formação e as "novas" inserções do Estado na economia nacional surgiram uma série de pequenas e médias cidades, muitas das quais

\footnotetext{
${ }^{1}$ Após 1930, surgiram alguns estudos mais sistemáticos sobre a rede urbana do país (como os de Pedro Geiger e os associados ao IBGE), não obstante a falta de continuidade nesse âmbito temático.

${ }^{2}$ Neste período apontavam-se seis cidades do Vale do Jequitinhonha classificadas como médias: Almenara, Araçuaí, Diamantina, Jequitinhonha, Pedra Azul e Salinas. Ver: Amorim Filho, O. B., Bueno, M. E. T. e Abreu, J. F. (1982).

${ }^{3} \mathrm{Na}$ realidade o ouro foi descoberto na região central de Minas no último decênio do século XVII e o diamante na segunda década do século XVIII, na região do Tijuco, atual Diamantina.
} 
amplamente esquecidas pela historiografia convencional. A difícil incorporação destas localidades pelos sistemas mais dinâmicos da economia nacional colocou-as, de certo modo, à margem do processo de desenvolvimento, não obstante o fato de várias delas já terem desempenhado um importante papel histórico na estruturação sócio-espacial do território mineiro. Entre estas é possível destacar aquelas que têm sua origem ligadas aos primórdios de Minas Gerais: os "lugares urbanos"4 surgidos com o ciclo do ouro, alguns deles localizados no Vale do Jequitinhonha, no nordeste mineiro.

Para pesquisar estes lugares, foram adotados cortes analíticos temporais e espaciais. Espacialmente, foram adotados os limites da Macrorregião de Planejamento VII de Minas Gerais. Temporalmente, os limites desse trabalho encontram-se entre o século XVIII e fins do XIX, quando diversas mudanças políticas, econômicas e sociais configuraram uma nova etapa da história do país (Iglésias, 1970).

Pretende-se aqui tratar de maneira abrangente, do surgimento dos primeiros núcleos populacionais urbanos significativos da região, tendo em vista a espacialidade que tais processos envolveram à época, uma vez que a configuração atual do Vale do Jequitinhonha é fruto desse processo histórico. As principais observações dirão respeito às atividades sócio-econômicas, principalmente as atividades minerária e garimpeira, bem como a pecuária de corte, de caráter extensivo, todas elas importantes enquanto vetores das primeiras entradas na região (e posterior ocupação), e fundamentais para a compreensão da dinâmica de estruturação de localidades urbanas rurais.

\section{2- A GENÊSE DA ESTRUTURA ESPACIAL}

Em 1693 as Capitanias do Rio de Janeiro, de São Paulo e de Minas Gerais eram uma só. Com a descoberta das "minas", o Rio de Janeiro é separado de São Paulo e Minas, que integravam uma única Capitania até 1709. Finalmente em 1720 a Capitania Real de Minas Gerais é separada de São Paulo. ${ }^{5}$ Os objetivos mais imediatos desta redivisão administrativa

\footnotetext{
${ }^{4}$ A idéia de "lugar urbano" deve remeter às noções de infra estrutura urbana e de rede. Ambos os aspectos são fundamentais para que se possa levantar hipóteses sobre o maior ou menor significado da rede de localidades do Vale do Jequitinhonha nos Séculos XVIII e XIX. A simples constatação de que um lugar foi primeiramente povoado não é suficiente para elevá-lo à categoria de "lugar urbano". Muitos destes lugares não atingiram níveis de infra estrutura e articulação espacial capazes de justificar a sua inclusão na categoria de "lugar urbano."

5 Embora hoje estas divisões espaciais pareçam mais claras, à época da Colônia e mesmo no Império, as superposições das divisões funcionais no espaço produziam uma precisão muito menor. Caio Prado quando se refere aos órgãos da administração geral e civil alertava para o fato de que incluíam-se aí "tanto funções propriamente administrativas (em nossa terminologia moderna), como de justiça." (Prado Júnior, 1973:313). Estudando o período, Paiva e Martins (1985:9) corroboram esta tese quando dizem: "Parece válido supor que, não havia em 1831, uma divisão político administrativa clara." Um resumo da divisão administrativa para a período colonial pode ser assim entendido: a maior unidade administrativa era a Capitania, sendo esta dividida em unidades judiciárias, as comarcas. Minas era dividida em três comarcas em 1714: Vila Rica; Sabará - Rio das Velhas; São João del Rei - Rio das 
estão ligados à tentativa da Coroa de controlar mais efetivamente a região das minas. As revoltas de Vila Rica e Pitangui contra a cobrança do "quinto" no início do século XVIII, deixaram claro à Portugal esta necessidade (Paula, 1988: 452-65).

\subsection{Entradas e Caminhos}

A região do sertões, posteriormente denominada "das Minas", já era muito conhecida dos Bandeirantes. Os diversos caminhos que davam acesso ao interior da Colônia eram trilhados periodicamente, seja em busca de nativos para serem escravizados, seja à procura de ouro e pedras preciosas. Embora o litoral tenha sido primeiramente ocupado, boa parte do interior vinha, concomitantemente, sendo progressivamente ocupada (Petrone,1970:127-58). Importantes atividades econômicas, postos avançados destes processos, foram sem dúvida a cana de açúcar ${ }^{6}$ e a criação de gado.

De fato, a pecuária bovina passara a representar um dos mais significativos vetores da ocupação do espaço brasileiro, ao penetrar lentamente no interior da Colônia. ${ }^{7}$ A ligação da pecuária com a indústria açucareira foi muita estreita. A expansão dos engenhos pelo litoral nordestino, vinha acompanhada da expansão da criação do gado "vacum", essencial para o fornecimento de couro, carne e animais de tração. A partir principalmente da Bahia e de Pernambuco, os currais foram se estendendo, tanto para o norte quanto para o sul. O rio São Francisco, neste sentido, teve um importante papel ao servir de aguada permanente, sendo as terras do seu grande vale uma importante fonte de sal. ${ }^{8}$ Foi, sem dúvida, a estrada natural para o transporte do gado, facilitando a penetração para o interior, rumo às áreas à montante do grande curso d'água. Assim, na última década do século XVI, a penetração da pecuária alcançava terras do sertão baiano e pouco depois atingia o norte

Mortes; passa a quatro comarcas em 1720 com a criação da comarca do Serro Frio; a cinco com a de Paracatu em 1815 e a seis com a de São Francisco em 1820. As comarcas se dividiam em termos, com sedes nas vilas ou cidades; os termos se dividiam em freguesias (divisão eclesiástica que forma a paróquia mas que também servia à administração civil). As freguesias por seu turno se dividiam em bairros, de limite e caráter extremamente imprecisos. Ver: Prado Júnior (1973:306); Paula (1988: 58-65) e Carvalho (1922).

${ }^{6}$ A cana de açúcar, nativa da Índia, foi trazida pelos portugueses para o Brasil a partir das ilhas da Madeira, Canárias, Cabo Verde e São Tomé. Rapidamente a cultura se espalha, principalmente pelo litoral nordestino. Em meados do século XVII a Colônia se torna o maior produtor mundial de açúcar. Inúmeros engenhos foram estabelecidos durante os séculos XVI e XVII. Ver: Pereira (1977: 9-45).

${ }^{7}$ A primeira remessa de gado bovino remonta à vinda da frota de Tomé de Souza, que chega à Colônia em 1549 trazendo entre outras coisas, algumas cabeças de gado. Em 1550 novo desembarque de bovinos. O então Governador-geral ordena a mesma caravela, a "Galga", a fazer novo carregamento do mesmo gado em Cabo Verde. Em 1552 já aparece a "Casa da Torre de Garcia D’Ávila", grande sesmaria que a partir da Bahia, em Tatuapara, alcança o rio São Francisco através de Sergipe, ocupando grande parte do sertão baiano. Cf.Holanda (1972: 117, v.1) e Azevedo (1970: 379).

8 "O sal é um dos productos naturaes mais interessantes do valle de São Francisco" (Sampaio, 1938:80). O sal existente nas suas "salinas", o famoso "sal gema", "lambedouros" dos bois, foi fator decisivo para expansão da pecuária nesta região e posteriormente no médio e baixo vale do rio Jequitinhonha, que também possuim numerosas "salinas". Sobre este fato é interessante lembrar o monopólio do sal, que, entre tantos, outros afetou diretamente a economia da Colônia entre 1665 e 1795, ano em que uma carta régia de 27 de maio o extingue. Ver: Frieiro (1966:166); Prado Júnior (1973:54) e Guimarães (1960:63-9).

Cadernos do Leste

Artigos Cientificos

Belo Horizonte, Edição Especial, 2000 a 2008 
de Minas Gerais. Com a mineração, no início do século XVIII, os espaços mineiros passam a ser efetivamente povoados.

Convém observar, conforme salienta Alisson (1960:73), que os caminhos raramente eram feitos em áreas carentes de água, daí a preferencia pelos vales em detrimento das chapadas, que só foram utilizadas como caminho muito tempo depois. Os vales, além de serem rota segura contra os obstáculos do relevo, possuíam, com freqüência, fontes de água perene, o que delineava rotas de trafego que tendiam a se tornar permanentes.

O gado, percorrendo e emoldurando tais rotas, torna-se então fundamental como suporte à vida dos que se aventuraram em busca do ouro provenientes da Bahia, e das área ao sul da Colônia. O consumo anual de carne no período da mineração implicava no abate de cerca de 18 a 20 mil bois/ano, havendo necessidade de fornecimento permanente, conseguido inicialmente através de contratos estabelecido pelo governo local com fornecedores de outras regiões.

$\mathrm{Na}$ verdade a região de mineração encontrara nos muares, burros e mulas, os animais mais apropriados às atividades extrativas e mais adaptados aos difíceis caminhos da região. $\mathrm{O}$ transporte de cargas, inicialmente efetuado por escravos, passa posteriormente a ser feito por burros e mulas. Só muito depois as estradas tornaram-se "carroçáveis". ${ }^{10}$

\subsection{Atividades Econômicas e Rede Urbana}

A produção de espaços, embora pouco explorada em estudos de história econômica, é um dos resultados mais eloquentes dos processos socioeconômicos. A dimensão socioespacial como eixo de reflexão é, na verdade, primordial para a compreensão desses processos, contribuindo para integrar novos elementos à pesquisa em Ciências Sociais.

Os textos clássicos sobre história do Brasil sempre salientaram a grande importância dos "ciclos econômicos" para estruturação do seu território. Hoje, à luz de

\footnotetext{
${ }^{9}$ A qualidade do gado era, no entanto, pouco satisfatória. Apesar do seu importante papel no processo de ocupação do interior, como fonte de alimento e de tração, eram geralmente animais pequenos, de origem europeia e pouco adaptados aos trópicos. Seu peso em carne alcançava cerca de 120 quilos e sua força como animal de tração era deficitária para a maioria dos trabalhos. Esta situação só irá melhorar muito mais tarde, a partir de fins do século XIX e início do XX, com a importação de reprodutores e matrizes de origem indiana (zebu e gir), mais adaptados ao tipo de clima, mais robustos e resistentes para o trabalho e de maior tamanho tendo portanto mais peso na hora do abate. Ressalte-se que o gado bovino, muito empregado como animal de tração nas áreas litorâneas e mesmo em regiões mais descampadas e de relevo suave do interior da Colônia, não apresentava as mesmas vantagens quando utilizado em regiões de relevo movimentado e de difícil acesso. O maior interesse pelos bovinos nestas regiões devia-se ao seu emprego como fonte de alimento e fornecedor de couro (do qual eram feitas as "solas"). A sua utilidade como animal de tração limitava-se a alguns serviços mais pesados. Ver inclusive Frieiro (1966:203). ${ }^{9}$ Ver à propósito Azevedo, (1970.379-381); Holanda, (1972:218-227) e Prado Júnior, (1973: 254-257).

${ }^{10}$ Ver à propósito Azevedo, (1970.379-381); Holanda, (1972:218-227) e Prado Júnior, (1973: 254-257).

Cadernos do Leste

Artigos Cientificos

Belo Horizonte, Edição Especial, 2000 a 2008
} 
novos estudos, realiza-se uma ampla revisão desse tipo de abordagem, em face de sua notória insuficiência para cobrir outras dimensões da vida colonial, pouco visíveis, mas igualmente essenciais à compreensão de estruturas socioespaciais pretéritas, ainda vivas hoje. ${ }^{11}$ Essas dimensões dialogam mais de perto com as localidades onde, em última instância, desenvolviam-se as atividades econômicas, processavam-se as trocas, os ganhos, as relações e as implantações.

A exportação, atividade à qual se encontram ligados esses "ciclos", sempre foi privilegiada na economia colonial. Mas exportar não era a única atividade econômica de peso na Colônia. Desde a descoberta do ouro, e posteriormente do diamante, ou mesmo um pouco antes, a produção e circulação de mercadorias não era desprezível. ${ }^{12}$ Neste particular, o Vale do Jequitinhonha apresenta características singulares. A ocupação de seu território vinculava-se à lógica da exportação de riquezas minerais de alto valor e fácil contrabando. Diante de sua localização e atributos geográficos, tornou-se uma região que despertava, com justa razão, enormes suspeitas das autoridades coloniais.

Outros aspectos notáveis que singularizam a Região dizem respeito à formação de cidades e à proximidade com a Bahia. A rede urbana que surge no século XVIII, diretamente associada aos achados em ouro e diamante, sofre importantes alterações no século seguinte, quando a presença baiana torna-se expressiva no Baixo e Médio Jequitinhonha.

O posterior deslocamento do eixo econômico, gradativamente a favor das áreas meridionais do país, acarretou modificações na dinâmica interurbana de Minas Gerais. Contudo, em desacordo com os clássicos da historiografia brasileira, não houve uma decadência que teria se operado de imediato nas áreas centrais e nordestinas de Minas, após o declínio da mineração no século XVIII.

Alguns autores contemporâneos afirmam que a economia mineira setecentista e oitocentista, era claramente mercantilizada e monetizada. Só assim se explicaria a grande aquisição de escravos e o expressivo comércio de exportação e importação com áreas do Rio de Janeiro, São Paulo e Bahia, mesmo após o ápice do período minerador (Paiva, 1996). Os fluxos de mercadorias justificariam uma estrutura urbana mais complexa e a

\footnotetext{
${ }^{11}$ Como as formas de formação e relacionamento familiar no âmbito das redes sociais e inter-raciais que modelavam a brasilidade em construção, aspecto chave para o entendimento das dinâmicas econômicas regionais do Brasil Colonial

${ }^{12}$ Até a década de 60 muitas das análises publicadas sobre a história de Minas Gerais, principalmente sobre o período compreendido entre os séculos XVIII e XIX situavam-na sob o signo dos grandes ciclos econômicos, considerando menores os aspectos particulares da economia mineira. O resultado foi a produção de trabalhos que não puderam identificar a rica dinâmica interna da região. A partir da década de 70 no entanto, surgem pesquisas que começam a definir com maior precisão esta dinâmica. A década de 80 é caracterizada pelo aparecimento da temática do mercado interno nos estudos de caráter histórico. Cf. Chaves (1995) e Meneses (1997).
} 
existência de uma rede de lugares de certo destaque para a época.

Mesmo com o declínio da mineração nas áreas centrais da Capitania, o período que se estende entre o final do século XVIII até a metade do século XIX é rico em diversidade econômica, inclusive à sul e nordeste, com a generalização mais efetiva da agropecuária; a continuidade do desenvolvimento comercial; e a introdução de práticas agrícolas que preparariam o território para experiências de acumulação mais significativas na segunda metade do século XIX. Além disso, ainda era forte a perspectiva de novos surtos de geração de riqueza derivada da mineração, tanto por parte da Coroa, quanto por parte dos milhares de indivíduos dispersos pelas cabeceiras dos córregos. Convém ressaltar que tais pessoas dominavam perfeitamente as técnicas mais usuais de extração de ouro e pedras preciosas. $\mathrm{Na}$ verdade, eram frequentes ainda tais achados, o que despertava grande desconfiança da Coroa, a ponto de ter interditado durante muitos anos o acesso à Demarcação Diamantina.

A segunda metade do século XIX apresentou elementos novos e fundamentais que vieram afetar a estruturação da região. Dentre tais elementos cabe destacar três: as alterações na estrutura da mão de obra com o fim da escravidão; o deslocamento do eixo dinâmico da economia nacional, da mineração para o café; e as alterações na política nacional, com o advento da República. Tudo isto provocaria desdobramentos globais em favor da Zona da Mata e Sul de Minas, Vale do Paraíba e, finalmente, Planalto Paulista, resultando na expansão sem precedentes da economia paulista.

\section{3 - O Vale do Jequitinhonha e a Expansão do Centro de Minas}

A região hoje conhecida como Vale do Jequitinhonha foi uma das primeiras a ser ocupada em Minas Gerais. Sua história remonta às primeiras Entradas, mas foram o ouro e as pedras preciosas que jogaram um papel primordial na estruturação de seu território.

Por meio das bandeiras seiscentistas, descobriu-se ouro na região do córrego do Tripú, hoje Ouro Preto. ${ }^{13}$ A partir de então, diversas outras bandeiras penetraram no território mineiro, dando início à efetiva ocupação do interior. Esta ocupação iniciada no século XVII e continuada durante todo o século XVIII, teve como principais vetores

\footnotetext{
${ }^{13}$ É importante observar que o ouro e mesmo o diamante, entre outros metais preciosos e gemas, já haviam sido descobertos na Colônia antes deste período e em outras áreas. A sua exploração contudo não era significativa devido a diversos fatores de ordem natural e mesmo outros de ordem econômica, administrativa e tecnológica. Cf. Holanda (1973:229-58). A bem da verdade, somente quando a Coroa passou a reconhecer e premiar os garimpeiros com títulos de propriedade das lavras é que ‘explodiram' as descobertas nas Minas Gerais.

${ }^{13} \mathrm{O}$ termo garimpeiro tem origem na palavra "grimpa" que quer designar "o ponto mais alto; cocuruto, crista" do relevo, onde estes trabalhadores clandestinos escondiam-se quando perseguidos, devido ao caráter ilegal da sua atividade. Cf. Santos (1976: 77) e Rocha (1984:42).
} 
econômicos a extração mineral (na sua variante legal, a mineração, e na ilegal, o garimpo) ${ }^{14}$ e a pecuária, esta muito significativa enquanto atividade permanente, que lenta mas constantemente ocupava o interior. A área central da Capitania e a região do Vale do Jequitinhonha, notadamente o Alto Jequitinhonha, passaram a constituir importantes áreas de atração de população. Tudo isso viria estimular a urbanização vis-à-vis o desenvolvimento de uma economia gradativamente voltada para o mercado interno. ${ }^{15}$

"Nenhuma atividade econômica teve (...) maior influência na criação e no desenvolvimento das cidades do interior e, portanto, na produção do fenômeno urbano do que a indústria mineradora, não só na região das "minas gerais", como, pelas suas repercussões, sobre o centro comercial e político que deslocou para o Rio de Janeiro.” (Fernandes, 1975: 144).

Os caminhos para as Minas, importantes elos de conexão com a rede urbana em formação, inicialmente trilhados pelas bandeiras e posteriormente muito utilizadas quando da mineração, resumiam-se a três: o de São Paulo (caminho velho); o do Rio de Janeiro (caminho novo); e o da Bahia, também antigo e que apresentava duas variantes, uma pelo Vale do São Francisco e outra, pelo rio Gavião em direção ao atual município de Rio Pardo. ${ }^{16}$

O surgimento de uma rede de lugares urbanos na região central de Minas, que se estendeu ao Alto Vale do Jequitinhonha, vinculou-se, de outra parte, à necessidade de um controle mais efetivo das áreas mineradoras. ${ }^{17}$

"Ao contrário do que se dá na agricultura e em outras atividades da Colônia, a mineração foi submetida desde o início a um regime especial de minuciosa e rigorosa disciplina." (Júnior,1973: 174).

Isto levou à criação de 16 vilas e do Distrito Diamantino ${ }^{18}$ durante o período colonial, sendo 14 delas ainda no século XVIII. A finalidade destas vilas era fundamentalmente impor ordem à desordem que se configurava em diversos povoados e, naturalmente, recolher os tributos. Duas localidades foram de fundamental importância nesse sentido: Ouro Preto, na área central, e Serro, a nordeste. Ambas surgiram no período

\footnotetext{
${ }^{15}$ Caio Prado define a área de maior adensamento populacional à época em Minas como sendo aquela localizada "numa faixa que se estende de sul a norte, da bacia do rio Grande às proximidades das nascentes do Jequitinhonha, mais ou menos entre os pontos em que se formam a vila de Lavras e o arraial do Tejuco". Prado Júnior (1973:57).

${ }^{16}$ Conforme observam Antonil, (1711) em sua "Cultura e opulencia do Brazil por suas drogas e minas"; Prado Júnior (1973:243-5) e Paula (1988:127-132).

${ }^{17}$ Sobre estes aspectos a leitura da conhecida obra "Memórias do Distrito Diamantino" de Joaquim Felício do Santos é esclarecedora.

${ }^{18}$ Cabe notar que a relevância do povoado na rede pode não estar diretamente relacionada à sua posição na hierarquia jurídico-administrativa existente, embora esta posição seja um indicador da sua maior complexidade no que se refere aos serviços administrativos. Assim, o Tejuco (Diamantina), premido pelo Regimento da Demarcação Diamantina,continuou arraial durante todo o período colonial, sendo elevado a vila somente em 1831, não obstante sua clara feição urbana."Com a criação do Distrito Diamantino, o Tejuco continuou arraial, e o Serro foi uma espécie de capital daquela área” (Paula, 1988:56-57).
} 
compreendido entre o fim do século XVII e início do XVIII como fruto da busca por minerais preciosos.

Vila Rica, atual Ouro Preto, uma das três primeiras vilas de Minas Gerais, foi criada no ano de 1711. As outras duas seriam a do Ribeirão do Carmo, atual Mariana, única cidade mineira oficial do período colonial e a Vila Real de Nossa Senhora da Conceição de Sabará, hoje Sabará. ${ }^{19}$ Mais próxima do Rio de Janeiro, Vila Rica, cujo crescimento tornara-se muito expressivo, viria tornar-se capital da Capitania em 1721.

Serro, por outro lado (elevado à Vila do Príncipe e cabeça de comarca em 1714) ${ }^{20}$, localizada na Serra do Espinhaço, no Alto Vale do Jequitinhonha, tinha o seu acesso dificultado pelo relevo movimentado e distância em relação à região central da Capitania. A dificuldade de integração com o centro das Minas também associava-se ao interesse único da Coroa portuguesa em promover formas de exploração restritiva, de tipo predatório, sem cogitar da criação de estruturas capazes de sustentar posteriormente um desenvolvimento socioeconômico mais consistente. Ao contrário, a manutenção de redes de acesso precárias e a obscuridade das rotas e da estrutura interna da região dos diamantes, encontrava na política da metrópole todo o apoio.

Contudo, apesar desses obstáculos, surgiram alguns núcleos populacionais de importância no interior da Serra do Espinhaço. A estruturação de uma rede de lugares no Alto Jequitinhonha, apesar de ser periférica ao centro mineiro, se mostraria bem articulada internamente e integrada a outras localidades fora da região. As trocas comerciais, entre as localidades e o litoral, extremamente lucrativas para os tropeiros e comerciantes, mantiveram-se não obstante as interdições da Metrópole. A Coroa entendia, por razões óbvias, ser o comércio um dos principais meios nos quais se processava o contrabando. Outro aspecto fundamental que explica a expansão territorial e dos entrepostos comerciais relaciona-se aos preços alcançados pelos produtos na região das Minas, muito superiores aos praticados nas outras áreas da Colônia, tendo no ouro em pó a sua moeda corrente.

Trabalhos históricos recentes contestaram estudos anteriores que postulavam a falta de dinamismo em regiões que não contassem com o ouro e diamantes ou forte agricultura de exportação. Sabe-se hoje que apesar da fundamental importância destas riquezas para a estruturação do Vale do Jequitinhonha, não seria possível compreende-la sem levar em consideração a agricultura e a pecuária, inicialmente voltadas para a subsistência mas posteriormente engajadas num circuito comercial que visava os mercados interno e externo

\footnotetext{
${ }^{19}$ Ver: Paula (1988:55-65) e Costa (1970:16-21)..

${ }^{20}$ Esta data é polêmica. Teophilo Feu de Carvalho discorda francamente dela estabelecendo o ano de 1720 como o da criação da Comarca do Serro Frio e da Vila do Príncipe (Serro). Carvalho (1922: 21-42). 
ao Vale.

Apesar das dificuldades impostas pelo meio geográfico (relevo e condições climáticas) e as dificuldades de natureza econômico-social, a região conseguiu estruturar-se em uma rede de lugares significativa no contexto da Capitania. Esta rede, em grande medida ainda presente na atualidade, sofreu ao longo da história significativas mudanças. Algumas localidades, inicialmente importantes, hoje são apenas coadjuvantes na rede urbana; outras surgiram ou ressurgiram mais recentemente, envolvidas em distintas dinâmicas econômicas, tais como a pecuária, o café, a aguardente e até mesmo o turismo; algumas no entanto permaneceram em lugar de destaque durante toda a história da região, embora nem sempre tenham se mantido fiéis às mesmas atividades econômicas predominantes quando do seu surgimento.

\section{3 - A REDE DE LUGARES URBANOS DO VALE DO JEQUITINHONHA}

A análise subsequente foi empreendida a partir de consultas a documentos e mapas históricos tais como: o trabalho de Teophilo Feu (Carvalho, 1922); o manuscrito de José Joaquim da Rocha de 1781, Geografia Histórica da Capitania de Minas Gerais, reeditado na Coleção Mineiriana em 1995; as tabelas sobre estimativas populacionais cedidas por Clotilde Paiva (in Paiva, mimeo 1997); o censo demográfico de 1872; o trabalho de Maria C. S. Martins (Martins, mímeo, 1997); os dicionários histórico-geográfico e toponímico escritos por Barbosa (1971) e Costa (1970); o mapa relativo ao início do século XIX de Carrato; o tratado de geografia descritiva de José J. Silva de 1877, reeditado pela Coleção Mineiriana em 1997; outros mapas antigos editados nos séculos XIX e XX, a exemplo de Soares, 1925; e sucessivas visitas de reconhecimento de campo feitas à região em estudo.

Trata-se de uma tentativa exploratória de reunir material analítico na forma de cartogramas e mapas temáticos que absorvam informações dispersas em diferentes fontes documentais. As informações uma vez espacializadas trazem maior clareza, para os estudiosos e público em geral, sobre importantes fatos geoeconômicos que pertencem a história da formação das localidades. Por essa razão privilegia-se sempre a inserção dos nomes dos povoados e lugares urbanos nos cartogramas segundo a denominação atual, deixando as denominações antigas em quadro anexo no corpo do texto, da mesma forma que utiliza-se simplificadamente de segmentos de reta como recurso para mostrar tão somente as articulações entre as localidades, como se representassem a estrutura de caminhos da região. 
A consulta a documentos referidos a história administrativa de Minas foi útil para o conhecimento da hierarquização existente entre as localidades. Ao se adicionar a verificação de trilhas, caminhos e estradas existentes, no período em análise, foi possível estabelecer por dedução, as categorias de lugares urbanos mais importantes e menos importantes (constantes das legendas dos mapas esquemáticos 1, 2 e 3).

A definição de lugar urbano não é tarefa fácil, em face não só das definições oficiais de Cidade e Vila, inadequadas à realidade dos fatos urbanos em Minas Gerais, mas também em decorrência dos casos obscuros em que determinados povoados situavam-se na condição de sede de comarcas, termos e freguesias, sem contar, todavia com o mínimo de equipamentos que pudessem qualificá-los como uma localidade urbana. ${ }^{21}$

Resumidamente, os lugares urbanos, entre os séculos XVIII e XIX, envolveriam a presença: de casario aglomerado em pequena área física; arruamento (ainda que mínimo); equipamentos relacionados à gestão territorial da época (como instituições administrativas, coletorias, postos de vigilância); existência de práticas regulares de comércio e eventuais sistemas de transportes. A consulta à rede de caminhos foi um recurso básico utilizado para a dissolução de algumas dúvidas com relação a definição e hierarquia desses lugares.

Com relação ao tamanho das populações urbanas, as consultas aos dados de Clotilde Paiva e aos dados do Censo Demográfico de 1872 foram importantes como meio de se estabelecer a hierarquia e os pontos da rede. Note-se contudo, que tais populações eram freqüentemente muito pouco expressivas ao se considerar os tamanhos populacionais de nossas cidades na atualidade. Examinar esta questão com os olhos da época é sempre um desafio. Ainda recentemente, é bom lembrar, a própria definição do IBGE de lugar urbano é suscetível de controvérsias, já que, por exemplo, em 1958, na Enciclopédia dos Municípios, eram definidas como urbanas as localidades que reuniam mais de 500 pessoas residindo nas sedes municipais.

\subsection{A Formação e Desenvolvimento da Rede de Lugares Urbanos}

Serro, Diamantina e Minas Novas, os lugares urbanos mais importantes do Vale do Jequitinhonha começaram as se consolidar no século XVIII (ver Mapa 1).

Serro era a Cabeça da Comarca do Serro Frio desde 1720 (Carvalho,1922: 21-58). Diamantina, antigo Tijuco, arraial pertencente à Vila do Príncipe fora elevado a vila em 1831, sendo o primeiro lugar onde foram descobertos diamantes, tornando-se o centro

\footnotetext{
${ }^{21}$ Ver a dissertação de mestrado de André Velloso, defendida em 1999 no IGC/UFMG.

Cadernos do Leste

Artigos Cientificos

Belo Horizonte, Edição Especial, 2000 a 2008
} 
administrativo da Intendência dos Diamantes da Demarcação Diamantina (Santos,1976: 45-57; Barbosa, 1971:162-63). Minas Novas, arraial elevado à vila em 1729, pertencia judicialmente à Comarca do Serro Frio mas administrativa e militarmente fizera parte da Comarca da Bahia até $1757^{22}$.

Estes três lugares constituíram os principais pontos da rede urbana que se esboçava, quer pelo caráter administrativo que possuíam, quer pela expressão das suas lavras minerais, quer pelo significativo contingente populacional que viria nelas estabelecer residência, e desenvolver práticas comerciais e de abastecimento.

Berilo, Itacambira e Rio Pardo podem ser considerados como lugares urbanos (ou pré-urbanos) de menor importância, embora funcionassem como pontos de ligação da rede com áreas mais distantes, internas ou externas ao Vale do Jequitinhonha. Berilo, um dos arraiais que surgiu nas proximidades de Minas Novas, "prosperou e foi elevado à freguesia" (Barbosa, 1971: 70). Itacambira, situada numa região de ocupação antiga, cujo processo de exploração mineral iniciou-se por volta de 1698 (Barbosa, 1971:224-25), era um dos principais pontos das rotas do comércio regional e inter-regional. Ligava-se ao registro de Inhacica, por onde passavam passageiros e mercadorias vindas de povoações da margem direita do rio São Francisco (Chaves, 1995: 117). Rio Pardo, freguesia criada em 1740, tornou-se próspera (Barbosa, 1971: 409-10), servindo como importante ponto de ligação entre o vale do Jequitinhonha e o sudoeste baiano. (Rocha, 1995; Carrato, 1968).

O Mapa 1 explicita ainda a importância de três articulações que integravam a rede urbana em formação: a que ligava Diamantina e Serro com o centro de Minas; a que ligava Diamantina a Itacambira, e daí com o vale do São Francisco através de São Romão; e a que ligava Rio Pardo com o São Francisco (já na Bahia) e o Sudoeste baiano pelas bacias dos rios Pardo e Gavião.

Até 1730, das nove vilas criadas em Minas, duas estavam na Comarca do Serro (Serro e Minas Novas). O número dos "registros" e a circulação de mercadorias indicam uma situação dinâmica em termos de trocas de mercadorias e fluxo de pessoas (Chaves, 1995; Meneses, 1997 e Paula, 1988). Assim, a materialização de uma rede urbana associada ao extrativismo mineral e ao comércio, localizada na grande Cordilheira do Espinhaço (Serro, Diamantina, Itacambira, Minas Novas, Berilo e Rio Pardo) constitui uma característica singular que tipifica a rede urbana do Vale do Jequitinhonha em relação a outras áreas da Capitania que vieram conformar redes urbanas. As dificuldades naturais de

\footnotetext{
${ }^{22}$ Quando o Conselho Ultramarino determinou sua incorporação ao território de Minas Gerais), tendo sido a $9^{\text {a }}$ vila de Minas Gerais e importante centro da mineração e agricultura no século XVIII. (Barbosa, 1971: 290-91; Hilaire,1975; Chaves, 1995).
} 
acesso, acrescidas às restrições impostas pela Demarcação Diamantina, não foram capazes de impedir o surgimento de um comércio significativo, que alicerçado na atividade mineradora começou a estruturar a rede de lugares urbanos.

Os obstáculos à penetração das frentes de ocupação, vale dizer, eram de diversos tipos. Certamente a presença da mata Atlântica existente na Bahia e em áreas mineiras foi um deles. Inicialmente as áreas escolhidas para a criação do gado eram os campos, naturalmente mais "limpos", como nas grandes várzeas do vale do São Francisco. No sertão baiano, a carência de rios perenes que pudessem garantir o suprimento de água, e o relevo constituído pelo Complexo do Espinhaço foram outros óbices dignos de nota. Correlatamente, a precariedades das comunicações e os conflitos entre brancos e índios ${ }^{23}$, permeavam os amplos espaços de penetração e articulação entre o Médio e Baixo Vale do Jequitinhonha, o centro mineiro e o sul-sudoeste da Bahia. A favor da ocupação da Região do Jequitinhonha e da penetração baiana pesou a condição de perenidade de seus rios, se comparados aos da Bahia.

Assim, a presença baiana no Jequitinhonha, desde o século XVIII, é comprovada pelo menos pelas seguintes evidências: a) participação expressiva de baianos na guerra dos Emboabas, cujo palco de conflitos estendeu-se por diversas áreas das "Minas Gerais"; b) a existência de caminhos naturais, de fácil circulação (vales fluviais amplos), que ligavam diferentes localidades do Jequitinhonha à parte baiana dos vales do São Francisco e Pardo; c) a maior antiguidade da economia baiana e sua relativa proximidade com Minas, que veio propiciar a geração de conhecimentos sobre o território (envolvendo o sertão e as áreas de matas ocupadas por tribos indígenas) e sobre atividades necessárias a sobrevivência (pecuária, agricultura e extrativismo) em áreas inóspitas da Colônia.

As ligações fluviais e a rede de caminhos ${ }^{24}$ que veio se estruturar ao longo dos vales fluviais foi um dos principais fatores que permitiriam a expansão da pecuária originária do Nordeste. Rios como o Jequitinhonha e o Pardo eram amplamente utilizados como vias de acesso do gado para nordeste de Minas (ver Mapa 1). Além disso, convém ressaltar que o contrabando, responsável pela abertura de muitos caminhos das Minas para outras regiões da Capitania, processava-se de maneira intensa pelos rios (a exemplo do rio São Francisco), pois estes apresentavam grandes dificuldades de fiscalização. Entre estas dificuldades é possível destacar aquelas que relacionam-se ao silêncio deste tipo de transporte bem como

\footnotetext{
23 Algumas tribos autóctones da região, genericamente denominadas de "Botocudos", eram reconhecidas pelos portugueses como constituída por povos bravios e avessos ao contato.

${ }^{24}$ Convém observar que os caminhos eram ainda incipientes, não carroçáveis, apenas para uso de pessoas e animais (gado bovino, asininos e muares). Todavia, sua utilização em termos de comércio interno e externo tornar-se-ia frequente, como demonstram recentes estudos relativos a abastecimento, pautados nas pesquisas sobre "registros" e postos fiscais (Chaves, 1995; Meneses, 1997).
} 
à rapidez e pouca necessidade de víveres para se fazer a jornada (que podia ser executada por apenas duas ou três pessoas comandando uma canoa). Embora o estabelecimento de quartéis às margens destes cursos d'água pudesse ser relativamente eficiente (sendo levada a cabo a partir do século XVIII), a construção e o funcionamento dos mesmos era uma tarefa difícil devido às distâncias dos centros de abastecimento e a obscuridade dos acessos. Em que pese todos estes aspectos, o estabelecimento destes quartéis e a posterior liberação da navegação do rio Jequitinhonha, foram importantes vetores de ocupação da área e do estabelecimento da sua rede de lugares urbanos.

Na primeira metade do século XIX, a expansão da rede de lugares urbanos (mapa 2), associa-se primordialmente à consolidação de pequenos núcleos garimpeiros que surgiram ainda no século XVIII. As proibições do Regimento Diamantino eram severas e a perseguição aos garimpeiros dentro das áreas da "Demarcação" imprimia à atividade grandes riscos. Some-se as estes fatores, a relativa carência de ouro e diamantes, que começou a se esboçar na segunda metade do século e que tornou ainda mais penoso o trabalho nas lavras. A procura de outras áreas, distantes dos lugares mais fiscalizados ou mesmo fora da área demarcada, resultou num movimento centrífugo de parte da população, concentrada no alto Vale do Jequitinhonha, em direção a outras áreas, notadamente aquelas localizadas nas proximidades de Minas Novas e ao longo do curso do médio Jequitinhonha. Alguns dos pequenos aglomerados que surgiram, após adquirirem uma maior consistência populacional e urbana, passaram a integrar a rede que começou a se esboçar no século XVIII. Com o relaxamento do Regimento Diamantino no início do Novecentos, estes lugares integrar-se-iam mais facilmente à rede urbana que emergia. O comércio que vinha se consolidando durante o século XVIII, passa a representar no século XIX uma importante atividade econômica. Os lugares urbanos surgidos desta expansão espacial, teriam na atividade comercial um importante complemento à mineração e ao garimpo. O abastecimento interno, em grande parte suprido pelos produtores da região desde meados do século XVIII, imprime um significativo movimento aos caminhos existentes forçando a abertura de novas rotas.

Recorde-se que, ainda no século XVIII, a região de Minas Novas tornara-se um centro garimpeiro, além de produtora de alimentos e entreposto comercial, dividindo então com o alto Jequitinhonha a polarização do Vale.

Destarte, não é ocioso ressaltar que comércio e o contrabando, foram importantes para a indicação dos vetores de ocupação no Vale do Jequitinhonha. Além dos caminhos para o Rio de Janeiro e São Paulo, havia a rota, muito utilizada, do São Francisco. De outra 
parte, se constituía outra rota de contrabando, por via fluvial ligando o alto Jequitinhonha a Belmonte $(\mathrm{BA}) \cdot{ }^{25}$ As proibições régias dos caminhos que levavam às Minas sinalizam para a importância do transporte fluvial, ainda no século XVIII. Com o relaxamento das restrições impostas ao Distrito Diamantino e a liberação da navegação pelo Jequitinhonha, a ocupação e povoamento da porção média e baixa da Região ganhou forte impulso. Ademais, viabilizava-se o acesso a jazidas minerais ainda não devidamente exploradas, ou exploradas ilegalmente.

De todos os modos, o desconhecimento do médio e baixo cursos do rio Jequitinhonha durante o século XVIII dificultou a sua utilização. Somente a partir de 1804, quando o Capitão Mor de Porto Seguro, João da Silva Santos sobe o rio a partir de sua foz em Belmonte, na Bahia (Sol, 1981: 15), é que a navegação do rio foi liberada (Santiago e Souza, 1996: 40). ${ }^{26}$

O Mapa 2, ao buscar evidenciar a rede urbana do Vale do Jequitinhonha em meados do século XIX expõe a notável expansão desses lugares, mormente através do reforço da rede de caminhos que já se esboçava no Mapa 1. Fazendas, capelas e povoados já existentes no século XVIII, localizados em pontos estratégicos da rede de caminhos ganharam desenvoltura assumindo a condição de lugares urbanos ${ }^{27}$. Além disso, ganham expressão as articulações entre localidades postadas ao longo do rio Jequitinhonha em direção à Belmonte, foz do rio no sul da Bahia.

Entre o Alto e o Médio Jequitinhonha várias pontos vieram se desenvolver ao longo do caminho entre Diamantina e Minas Novas, estruturando um subconjunto de localidades nas proximidades da confluência do rio Jequitinhonha com o rio Araçuá, no médio curso do Jequitinhonha. Entre estes lugares, considerados urbanos de primeira ordem, emergiam: Nossa Senhora da Penha, Itamarandiba, Turmalina e Chapada do Norte, todos tendo na mineração sua principal atividade econômica. No Alto Jequitinhonha, Diamantina, Serro e Gouvêia se destacavam, deixando Milho Verde em posição secundária, juntamente com Datas.

\footnotetext{
${ }^{25}$ Sabe-se que tribos indígenas da região eram exímias na arte de construir e manobrar canoas pelo rio. Essa técnica foi apropriada pelos exploradores brancos, que as utilizaram por muito tempo (até a década de 1960).

${ }^{26}$ Tudo indica, no entanto, que técnicas de navegação e construção de embarcações já eram utilizadas, ainda que esporadicamente. Belmonte, na foz do rio Jequitinhonha, que tornou-se um importante porto, sendo elevada a vila em 1764 (Cidade e Vilas, 1996: IBGE).

27 Cabe repetir que a seleção destes lugares urbanos foi feita com base, entre outros aspectos, nos tamanhos populacionais dos termos e/ou freguesias (dados de 1831-35), consulta a documentos históricos e pesquisas nos municípios, mas sempre considerando que o tamanho urbano deve ser referido aos padrões de tamanho das cidades à época. De qualquer maneira, ao se imputar a condição urbana procurou-se não discrepar em muito da definição oficial de paróquia (ou freguesia) que requeria a presença de 8000 "almas" na localidade (nas áreas rurais e urbanas). Em geral, freguesias e termos que abrigavam essa população possuíam um núcleo urbano de expressão. O corte de tamanho populacional mínimo aqui utilizado girou em torno de 6000 pessoas tendo em conta os números, por exemplo, do Censo de 1872.
} 
Além destas ocupações, outros surgiam e/ou se afirmavam na porção norte do Vale do Jequitinhonha, embora Rio Pardo e Grão Mogol ainda mantivessem maior expressão demográfica que Salinas e Itacambira.

No Médio-Baixo Vale, Araçuaí, Jequitinhonha e Salto da Divisa (nomes atuais) já exibiam uma posição importante na rede de localidades de meados do século XIX, não obstante a precariedade das comunicações por terra. Outros pequenos povoados já existentes, mas não constantes do Mapa 2, sinalizavam para o sentido da expansão da ocupação territorial que viria, pouco depois, reformatar a rede de lugares urbanos dessa porção regional. Exemplos dignos de nota são, certamente, os povoados de Pedra Azul, Águas Vermelhas, São João do Paraíso, Medina e Comercinho, já entrecortados de velhos caminhos ligados à Bahia, de onde vinham migrantes (especialmente de Vitória da Conquista e arredores) à procura de terras adequadas à agropecuária (algodão, cana e pecuária), conforme sugere o mapa de Rocha (1778).

A sul do Médio-Baixo Jequitinhonha, a presença de grandes extensões de florestas da Mata Atlântica, onde se localizavam os temíveis Botocudos, constituía ainda um obstáculo de difícil transposição, conquanto já existissem incursões ocupacionais que viriam, a partir da segunda metade do século XIX, desalojar os indígenas, liquidar com a floresta e pulverizar a rede urbana em direção ao que esboçava ser, em breve, Nova Filadelphia, atual Teófilo Otoni.

O Mapa 3 exibe a conformação mais provável do que deve ter sido a rede urbana da Região em fins do século XIX. De fato, o avanço do processo de urbanização foi importante, apesar de variar com a dinâmica oscilante das relações econômicas que vieram caracterizar as novas áreas incorporadas à rede.

No médio e baixo Jequitinhonha foi notável a expansão da pecuária a partir da instalação de fazendas por baianos, portugueses e mineiros, os quais beneficiaram-se de condições naturais favoráveis à formação de pastagens e expansão da pecuária de corte, além de contarem com a presença de um comércio dinâmico ao longo do rio Jequitinhonha e com a proximidade do tradicional mercado de consumo baiano.

Nesse sentido, Araçuaí, Jequitinhonha, Pedra Azul e Salto da Divisa comparecem na rede de lugares como áreas de importância estratégica, em face da função que passaram a desempenhar na pecuária de corte e no florescente comércio entre Minas e Bahia envolvendo gêneros alimentícios, tecidos, etc.

Mais ao norte, o caminho que unia Rio Pardo, Salinas e Virgem da Lapa ao resto da rede explicitava outro eixo estruturador articulado a Araçuaí e Minas Novas, 
favorecendo a consolidação destes lugares como nódulos de expressão econômico-espacial, por onde circulavam pessoas e mercadorias. ${ }^{28}$ De outra parte, Grão Mogol (e Cristália) perdia expressão, da mesma foram que Itacambira, provavelmente devido aos acessos difíceis a estas localidades e à posição deslocada em relação aos eixos de circulação mais dinâmicos que emergiam.

Ao sul, evoluíam as articulações com os vales dos rios Doce e Mucuri, como resultado de processos econômicos de ocupação do leste mineiro. Os empreendimentos centralizados em Nova Filadelphia e o avanço da criação de gado ${ }^{29}$ foram decisivos para a articulação entre tais regiões. Isto permitiria, mais tarde no século XX, a materialização do caminho que viria sediar um importante trecho da Rio-Bahia, e a afirmação de Teófilo Otoni como centro urbano que polarizaria várias das localidades do Médio e Baixo Jequitinhonha.

Embora o Mapa 3 só mostre parcialmente os caminhos entre Novo Cruzeiro, Padre Paraíso, Araçuaí e Teófilo Otoni, cabe ressaltar que este seria um dos vetores que produziriam a articulação entre as redes urbanas das respectivas regiões, durante boa parte do século XX.

\section{CONCLUSÃO}

Esse trabalho constitui um primeiro esforço exploratório de apresentar a rede de lugares de características urbanas e/ou semiurbanas da Região do Jequitinhonha, procurando salientar a sua importância no interior da economia mineira entre os séculos XVIII e XIX.

Foi necessário identificar as mudanças mais importantes que vieram impactar o processo de urbanização, explicitando suas articulações com os desdobramentos derivados da mineração e, paralelamente, com os fluxos populacionais originários da Bahia. O garimpo, a agropecuária e o comércio, fatores constitutivos da estrutura socioespacial. Forçaram a materialização de caminhos terrestres e fluviais que permitiriam introduzir maior vitalidade a rede de lugares do Jequitinhonha. Assim, atenção especial foi dada aos meios de transportes, pondo em relevo as limitações técnicas e as alternativas que se afiguravam na ocupação territorial, as quais foram se desenhando, por assim dizer, o que viria a ser a estrutura da rede de lugares urbanos da Região, visível até os dias de hoje.

\footnotetext{
${ }^{28}$ A literatura registra para o período um importante movimento econômico entre lugares postadas ao longo do rio Jequitinhonha, a partir de um rico comércio feito por canoas articulando o sul da Bahia e Minas Gerais, favorecendo expressivamente Araçuaí, Salto da Divisa, Jequitinhonha e outras localidades ribeirinhas.

29 Esse processo é mais característico das primeiras décadas do século XX, quando terras de excelente qualidade ficaram disponíveis, após retirada a Mata, e condições climáticas e de salinidade favoreceram a expansão da pecuária de corte, através da participação baiana e mineira (ver Guimarães, 1960 e Sol, 1980).
} 
Foi essencial assinalar os principais vetores socioespaciais da ocupação regional, sublinhando sua importância nos três momentos analisados no período. Os nexos de causalidade derivados dos arranjos institucionais protagonizados pela Coroa e população da área definida como "Demarcação Diamantina", que resultaram em um movimento de interiorização rumo ao Vale do Jequitinhonha foram especialmente relevantes, em face das especificidades econômico-espaciais que vieram aflorar, diferenciando de localidades em formação.

Embora periférica à rede de cidades do centro de Minas, as características singulares do Vale do Jequitinhonha foram, e ainda são em boa medida até hoje, capazes de realçar sua identidade. São questões que dizem respeito a importância histórica da extração de diamantes e pedras preciosas, as articulações e trocas populacionais com a Bahia e o resto do Brasil. Nesse sentido, registre-se a perversa trajetória da agropecuária, no Médio e Baixo curso do Vale, em face dos custos que a atividade imprimiu no espaço geográfico, no qual estavam presentes a Mata Atlântica, tribos indígenas e condições ambientais profundamente distintas das atuais.

Finalmente, cabe observar que as estruturas espaciais uma vez delineadas ganham características inerciais que geralmente resistem ao tempo, não obstante as mudanças que vão recobrindo a vida de relações dos lugares e populações locais. Assim, ainda hoje é perfeitamente possível visualizar a importância da rede de lugares que se desenvolveu no passado. Quaisquer alternativas de solução para o quadro de pobreza, que qualifica o Vale do Jequitinhonha, certamente deverão ter em conta a riqueza de seu processo de formação histórica. 


\section{REFERÊNCIAS BIBLIOGRÁFICAS}

CHAVES, Cláudia M. G. "Perfeitos Negociantes: Mercadores das Minas Setecentistas" Dissertação apresentada ao Curso de Mestrado na FAFICH/UFMG. Área de concentração: História das Relações Sociais de Dominação. Belo Horizonte, MG. 1995.

MENESES, José N. C. "O Continente Rústico: o abastecimento alimentar na Comarca do Serro Frio, 1750 - 1810" Dissertação de Mestrado em História apresentada ao curso de Pós - Graduação em História da FAFICH/UFMG. Belo Horizonte, MG. Jun/1997.

PAULA, J.A . "O Prometeu no Sertão: Economia e Sociedade das Minas dos Matos Gerais" Tese de doutoramento apresentada à FFLCH da USP. São Paulo, SP.1988.

SOUZA, J. M. "Cidade: momentos e processos - Serro e Diamantina na formação do norte mineiro no século XIX" Dissertação de Mestrado apresentada ao programa de Pós Graduação em Sociologia da Faculdade de Filosofia da UFMG. Belo Horizonte, MG. 1991.

FUNDAÇÃO JOÃO PINHEIRO/ CODEVALE. "Vale do Jequitinhonha - Diagnóstico preliminar" Belo Horizonte, MG. 1975.

LOPES, M. A . "A memória das tropas: recordações de tropeiros" in: Cadernos da FAFIDIA. AnoII . No 2. Volume 1. Diamantina, MG. Jun/Jul 1993.

MARTINS, M. L. "Mineração, agricultura e degradação ambiental em Minas Gerais nos séculos XVIII eXIX" in: Cadernos da FAFIDIA. AnoII . N ${ }^{\circ}$ 2. Volume 1.Diamantina, MG. Jun/Jul 1993.

MELO, H. P. "Ferrovias e café: Rio de Janeiro e Minas Gerais 1850/1910” in: Anais do VII Seminário sobre a Economia Mineira.(Diamantina, MG). Volume1. Belo Horizonte, MG. CEDEPLAR/UFMG. 1995.

SCLIAR, C. "Potencial Mineral do Alto Jequitinhonha" in: Cadernos da FAFIDIA. Ano I. No 1. Volume 1. Diamantina, MG. Out/1992.

ANTONIL, A .J. "Cultura e Opulencia do Brasil, por suas drogas e minas"(1711 - Lisboa). Rio de Janeiro. 1839

AVELLAR, H. A . "História administrativa e econômica do Brasil" Rio de Janeiro, GB. MEC/FENAME. 1970.

ÁVILA, A .(coordenação e redação definitiva). "Minas Gerais: monumentos históricos e artísticos. Circuito do Diamante" Coleção Mineiriana. Série Municípios e Regiões. Revista BARROCO No 16. Fundação João Pinheiro. Centro de Estudos Históricos e Culturais. Belo Horizonte, MG. 1994.

AZEVEDO, A. (org) "Brasil: a terra e o homem" Volume II. A Vida Humana. São Paulo. Companhia Editora Nacional/ Editora da Universidade de São Paulo. 1970.

AZEVEDO. Antônio C. A . "Dicionários de nomes, termos e conceitos históricos" Rio de Janeiro. Nova Fronteira. $2^{\text {a }}$ ed. 1997.

BARBOSA, W. A . "Dicionário Histórico-Geográfico de Minas Gerais" Belo Horizonte, 
MG.1971.

COSTA, J. R. "Toponímia de Minas Gerais - Com estudo histórico da divisão territorial administrativa” Belo Horizonte, MG. Imprensa Oficial do Estado. 1970.

COUTO, J.V. "Memória sobre a Capitania das Minas Gerais; seu território, clima e produções metálicas"(1799). Coleção Mineiriana. Série Clássicos. Fundação João Pinheiro. Centro de Estudos Históricos e Culturais. Belo Horizonte, MG. 1994.

FERNANDES, F.(organizador). "Comunidade e sociedade no Brasil: Leituras básicas de introdução ao estudo macro-sociológico do Brasil” São Paulo. Editora Nacional. $2^{\mathrm{a}}$ ed. 1975.

FERREIRA, J. P. (planejamento e orientação). "Enciclopédia dos Municípios Brasileiros" IBGE. Rio de Janeiro. 1957.

FRIEIRO, E. "Feijão, angu e couve: ensaio sobre a comida dos mineiros" Belo Horizonte, MG. $\quad$ Centro de Estudos Mineiros. Imprensa da UFMG. 1966.

GARDNER, G. "Viagem ao interior do Brasil, principalmente nas províncias do Norte e nos distritos do ouro e do diamante durante os anos de 1836-1841" Trad. Milton Amado. Belo Horizonte, Editora Itatiaia; São Paulo, Editora da Universidade de São Paulo. Coleção: Reconquista do Brasil. 1975.

HOLANDA, S. B. e Campos, P. M. (direção). "História Geral da Civilização Brasileira" São Paulo. Tomo I. Volumes $1^{\circ}$ "Do descobrimento à expansão territorial" e $2^{\circ}$ “Administração, Economia e Sociedade” Difusão Européia do Livro. 1972.

IGLÉSIAS. F. "Periodização da História de Minas Gerais", Revista Brasileira de Estudos Políticos, vol. 29, julho, 1970.

JACOB, R.(organizador)"Collectanea de Scientistas Extrangeiro(Assumptos Mineiros)" Volume II - Tomo I. Trad. Rodolpho Jacob. Belo Horizonte, MG. Imprensa Official de Minas Gerais. 1930.

MARTINS, A. L. "Breve História dos Garimpos de Ouro no Brasil" in: Rocha, G. A .(organizador) "Em busca do ouro: Garimpos e garimpeiros no Brasil" Rio de Janeiro. Editora Marco Zero. 1984.

PRADO JÚNIOR, C. “Formação do Brasil Contemporâneo” São Paulo. Brasileinense. 13a ed. 1973.

RESENDE, Maria E. L. e Moraes, A . M. “Atlas Histórico do Brasil” Belo Horizonte, MG. Editora Vigília. 1987.

SAINT-HILAIRE, A .(1779-1853). "Viagem pelas Províncias do Rio de Janeiro e Minas Gerais" Trad. Vialdi Moreira. Belo Horizonte, Editora Itatiaia; São Paulo, Editora da Universidade de São Paulo. Coleção: Reconquista do Brasil. 1975.

SALOMÃO, E. P. “O Ofício e a Condição de Garimpar” in: Rocha, G. A .(organizador) "Em busca do ouro: Garimpos e garimpeiros no Brasil" Rio de Janeiro. Editora Marco 
Zero. 1984.

SANTOS, Joaquim F.(1828-1895). "Memórias do Distrito Diamantino da Comarca do Serro Frio" Belo Horizonte, Editora Itatiaia; São Paulo, Editora da Universidade de São Paulo. Coleção: Reconquista do Brasil. 1976.

VASCONCELOS, Diogo P. R. "Breve descrição geográfica, física e política de Minas Gerais”(1807). Coleção Mineiriana. Série Clássicos. Fundação João Pinheiro. Centro de Estudos Históricos e Culturais. Belo Horizonte, MG. 1994.

VON ESCHWEGE, W.L. "Brasil, Novo Mundo" Trad. Domício de Figueiredo Murta. Coleção Mineiriana. Fundação João Pinheiro. Centro de Estudos Históricos e Culturais. Belo Horizonte, MG. 1996.

WALDICK, P. "Cana, café \& laranja; história econômica de Nova Iguaçu” Rio de Janeiro. Fundação Getúlio Vargas/SEEC. 1977.

AMORIM FILHO, O . B. ; Taitson Bueno, M. E. e Abreu, J. F. Cidades de porte médio e o programa de ações sócio-educativo-culturais para as populações carentes do meio urbano em Minas Gerais"in: Boletim de Geografia Teorética , Rio Claro: 33-46. AGETEO. 1982.

Azevedo, A . "Vilas e Cidades do Brasil Colonial.(Ensaio de geografia retrospectiva)" in: Revista "Terra Livre” No 10. São Paulo. AGB. 1994.

CORRÊA, R L. "Os Estudos das Redes Urbanas no Brasil até 1965" in: Simpósio de Geografia Urbana. Buenos Aires, Argentina. jun./ 1966. Publicação no 274 do Instituto Pan-Americano de Geografia e História. Rio de Janeiro. 1968

DIAS, L. C. "Redes: emergência e organização" in: Castro, I. E. ; Gomes, P. C. C. e Corrêa, R. L. "Geografia: conceitos e temas" Bertrand Brasil. Rio de Janeiro.

GEIGER, P. P. "Evolução da Rede Urbana Brasileira" Rio de Janeiro. GB. Instituto Nacional de Estudos Pedagógicos. MEC. 1963.

BOTELHO, T. R. e Paiva, C. A . "População e Espaço no Século XIX Mineiro: algumas evidências de dinâmicas diferenciadas" in: Anais do VII Seminário sobre a Economia Mineira.(Diamantina, MG). Volume1. Belo Horizonte, MG. CEDEPLAR/UFMG. 1995.

MATOS, R. "Aspectos econômicos e retrospecto histórico das migrações em Minas Gerais" in: Anais do VII Seminário sobre a Economia Mineira.(Diamantina, MG). Volume1. Belo Horizonte, MG. CEDEPLAR/UFMG. 1995.

RAISON, J. P. "Migração" in: "Enciclopédia Einaudi" v.8 Região. Porto, Portugal. Imprensa Nacional - Casa da Moeda. 1986.

SILVA, L. V. "Redescobrindo as cidades mineiras oitocentistas" in: Anais do VII Seminário sobre a Economia Mineira.(Diamantina, MG). Volume1. Belo Horizonte, MG. CEDEPLAR/UFMG. 1995.

PAIVA, Clotilde Andrade. "População e economia na Minas Garais do século XIX" Tese de doutorado. FAFICHL. USP. São Paulo. 1996. 
PAIVA, Clotilde Andrade. Tabelas sobre estimativas populacionais. in Paiva, mimeo 1997. Martins, Maria C. S. Tabelas sobre a divisão administrativa municipal de Minas Gerais. in Martins, mímeo, 1997.

CARRATO, José Ferreira. Igreja, Iluminismo e Escolas Mineiras Coloniais: notas sobre a cultura da decadência mineira setecentista. São Paulo: Cia. Editora Nacional/EDUSP, 1968.

MARTINS, Maria C. S. e Paiva, Clotilde Andrade. "População de Minas Gerais no século XIX" ; Martins, Roberto Borges e Martins, Maria C. S. "Novos estudos sobre a escravidão em Minas Gerais" Relatório de Pesquisa apresntado à FINEP. 1985.

CARVALHO, Teophilo Feu. "Comarcas e Termos: creações, suppressões, restaurações, encorporações e desmembramentos de comarcas e termos, em Minas Gerais (1709 1915)" Belo Horizonte, Imprensa Oficial, 1922.

ROCHA, José Joaquim da. "Geografia Histórica da Capitania de Minas Gerais" (1781) Coleção Mineiriana. Fundação João Pinheiro. Belo Horizonte, 1995.

COUTO, José Vieira. "Memória sobre a Capitania das Minas Gerais; seu território, clima e produções metálicas” (1799) Coleção Mineiriana. Fundação João Pinheiro. Belo Horizonte, 1994.

SILVA, José Joaquim da. "Tratado de Geografia descritiva especial da Província de Minas Gerais” (1877) Coleção Mineiriana. Fundação João Pinheiro. Belo Horizonte, 1997.

VASCONCELOS, Diogo Pereira Ribeiro de. "Breve descrição geográfica, física e política da Capitania de Minas Gerais" (1807) Coleção Mineiriana. Fundação João Pinheiro. Belo Horizonte, 1994. 